\title{
A differential PCR assay for the detection of c-erbB 2 amplification used in a prospective study of breast cancer
}

\author{
B A Jennings, J E Hadfield, S D Worsley, A Girling, G Willis
}

\begin{abstract}
Aims-To establish a robust differential polymerase chain reaction (PCR) assay for the detection of c-erbB 2 amplification in breast cancer that can be used in a routine pathology laboratory. Once established, the assay was used in a prospective study of breast tumours to investigate the relation between c-erbB 2 amplification and both recognised prognostic features and short term clinical outcome.

Methods-The differential PCR was used for the co-amplification of c-erbB 2 and a reference gene from 48 tumour DNA samples and control DNA samples. The ratio of the two genes was determined by image analysis of the PCR products electrophoresed on a highly resolving agarose gel. Results-The differential PCR assay was shown to be accurate and reproducible using the conditions outlined. Twenty six per cent of the breast cancer patients were shown to have c-erbB 2 amplification in their tumour biopsies. Twenty eight per cent of the patients died of their disease or had disease recurrence during the follow up period and $73 \%$ of these patients had amplification of c-erbB 2.

Conclusions-A significant association was found between c-erbB 2 amplification and early disease recurrence. This assay could be used to provide a marker for poor prognosis in breast cancer.
\end{abstract}

( Clin Pathol: Mol Pathol 1997;50:254-256)

Keywords: differential PCR; c-erbB 2; breast cancer

Molecular Genetics Department, Norfolk and Norwich Hospital, Norwich, UK

B A Jennings

J E Hadfield

S D Worsley

G Willis

\section{Histopathology \\ Department}

A Girling

Correspondence to: Dr Jennings, Molecular Genetics Department, Norfolk and Norwich

Hospital, Brunswick Road,

Norwich NR1 3SR, UK.

Accepted for publication 8 July 1997

The c-erbB 2 oncogene, also known as HER2 and neu, is located on chromosome 17 (q21-22) and encodes a $185 \mathrm{kDa}$ transmembrane protein that is a member of the erbB family of receptor tyrosine kinases. ${ }^{12}$ Frequently, c-erbB 2 is amplified and overexpressed in breast cancer and both of these abnormalities have been found to correlate with both disease recurrence and reduced overall survival. ${ }^{3-6}$

This paper describes a simple, robust, and highly sensitive differential polymerase chain reaction (PCR) method for detecting amplification of c-erbB 2 in a routine pathology laboratory. Differential PCR is a semiquantitative assay for the co-amplification of a target gene and a reference gene in the same reaction tube. ${ }^{7}$ The level of amplification of the target gene is seen by the ratio between the intensity of the two PCR product bands visualised on a gel. $\stackrel{\odot}{\varnothing}$ Other studies have examined a variety of $\tilde{\infty}$ differential PCR methods ${ }^{5-11}$ for the detection $\vec{O}$ of c-erbB 2 amplification, which has been $\overrightarrow{ }$ shown to correlate with $\mathrm{p} 185^{\mathrm{cerbB} 2}$ immunostaining, ${ }^{89}$ but only a few studies have examined the prognostic use of the assay with clinical follow up. ${ }^{5911}$

In this study, reliable measurement of c-erbB 2 amplification was achieved when the co- $\triangle$ amplification of the two gene sequences? (c-erbB 2 and $\beta$ globin) was optimised. The gene targets in this study are on different chro- $\bigcirc$ mosomes and so the results will reflect an 0 increase in the c-erbB 2 copy number irrespec- $\stackrel{\mathbb{Q}}{-}$ tive of whether a small region of the chromo- $\vec{\theta}$ some or the whole of chromosome 17 is duplicated. Chromosome aneuploidy, including loss and gain of chromosome 17 , is seen frequently을 in breast cancer.

The two primer pairs were selected to beฏे non-complementary at their 3 'termini and for their similar GC content. In addition, the PCR $\underset{F}{\Rightarrow}$ amplification was stopped before the end of the $\frac{\text { 의 }}{3}$ exponential phase of the reaction (the plateau) was reached.

We have analysed DNA extracted from $42 \stackrel{3}{3}$ breast tumour samples, most of which have? been described previously. ${ }^{12}{ }^{13}$ Short term clini-윽 cal follow up of the breast cancer patients revealed that c-erbB 2 amplification was associated strongly with early relapse. These data demonstrate that this assay identifies a subset of breast cancer patients with poor shorto term prognosis.

\section{Methods}

Samples from 42 female patients treated for primary breast cancer by the same surgical team between 1993 and 1994 were included in this study. The mean age of the patients was $63 \stackrel{\Phi}{\circ}$ years, ranging from 35 to 85 years. No woman had received preoperative radiotherapy. Fresho tumour samples were obtained from both mas- $\overrightarrow{\mathbb{D}}$ tectomy and excision biopsy specimens and DNA was extracted as described previously. ${ }^{12} \frac{\varrho}{\sigma}$ In addition to routine pathology examination, samples used for DNA extraction were exam -0 at least $70 \%$ tumour cells. The tumours ranged in size from $0.7 \mathrm{~cm}$ to $10 \mathrm{~cm}$ (mean 3.23). The selection criterion for inclusion in the study was that an adequate amount of tumour was available for the extraction of DNA.

DNA was also extracted from the peripheral blood of 10 of the breast cancer patients and 28 ined histologically and were shown to consist of 
normal individuals. In addition, DNA was extracted from two cell lines with known alterations of c-erbB 2 copy numbers: MCF7 may be hemizygous for c-erbB2 and SKBR3 has up to eightfold c-erbB 2 amplification. ${ }^{7}$ These samples served as controls for the optimisation of the assay.

All DNA was diluted to the same concentration $(50 \mathrm{ng} / \mu \mathrm{l})$. A dilution series of the SKBR3 DNA in normal DNA was prepared to test the linearity of the measurement achieved by the differential PCR.

The primers used were as follows. For c-erbB 2: 5'-TCGGAACGTGCTGGTCA AGA-3' (sense primer) and 5'-ATGGTACT CTGTCTCGTCAA-3' (antisense primer); these primers amplify a 91 base pair fragment from exon 3.

For $\beta$ globin: 5'-ACACAACTGTGTTCA CTAGC-3' (sense primer) and 5'-CAACTT CATCCACGTTCACC-3' (antisense primer); these primers amplify a 110 base pair fragment from exon 1.

DNA amplification was carried out in duplicate for each sample using a Progene thermal cycler (Techne, Cambridge, UK). Each $50 \mu \mathrm{l}$ reaction mixture contained $25 \mu \mathrm{l}$ PCR master mix (Boehringer Mannheim, Lewes, East Sussex, UK), $5 \mu \mathrm{l}$ of each primer $(50 \mathrm{pmol})$, $2 \mu \mathrm{l}$ of DNA (100 ng), and $13 \mu \mathrm{l}$ of sterile distilled water. Two controls that contained all the reagents but no target DNA were included with each batch. The reaction mixtures were prepared and kept on ice until the heating block of the thermal cycler reached the denaturation temperature $\left(94^{\circ} \mathrm{C}\right)$. Each reaction mixture was placed at $94^{\circ} \mathrm{C}$ for five minutes and then subjected to 35 amplification cycles; each cycle was 30 seconds at $94^{\circ} \mathrm{C}, 30$ seconds at $50^{\circ} \mathrm{C}$, and 30 seconds at $72^{\circ} \mathrm{C}$. This was followed by a final extension at $72^{\circ} \mathrm{C}$ for seven minutes. Initially, the optimum number of PCR cycles was determined empirically by analysing the amplification products after 20 to 50 cycles, at five cycle increments.

Amplification products were separated by electrophoresis using a 3\% metaphor agarose gel (Flowgen, Lichfield, Staffordshire, UK), stained with SYBR green DNA gel stain (Flowgen), and visualised by ultraviolet illumination. The sizes of the PCR products were compared with a molecular weight marker, pUC18 DNA digested with HaeIII (Sigma, Poole, Dorset, UK). The gel images were captured using a CCD camera linked to an image processing system (GDS 8000; UVP, Cambridge, UK). The intensity of the c-erbB 2 band and the $\beta$ globin band was determined for each specimen, by means of Gelworks software (UVP). These results were expressed as the ratio: intensity of the c-erbB 2 band/intensity of the $\beta$ globin band. The ratios determined for the tumour samples were converted into a measure of gene amplification using the ratios determined for the normal controls and cell line controls. The cut off point for amplification was the mean of the normal range plus two standard deviations (SD).

Univariate statistical analysis comparing clinical and laboratory findings was carried out using Fisher's exact test.

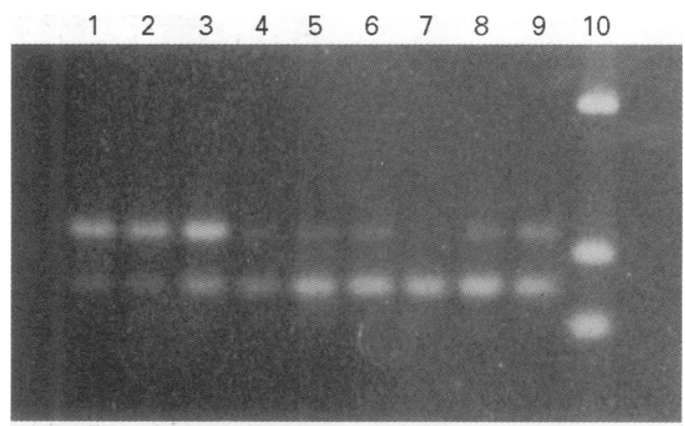

Figure 1 The amplification products from the differential $P C R$ of.c-erbB 2 and the reference gene $\beta$ globin from three normal DNA controls (lanes 1-3), from three breast tumours with amplification of c-erbB 2 (lanes 4-6), and from a dilution of SKBR3 DNA in normal DNA, equivalent to eight copies (lane 7), five copies (lane 8), and three copies (lane 9) of c-erbB 2. The 174, 102, and 80 base pair bands from the molecular weight marker ( $p U C 18$ DNA digested with HaeIII) are seen in lane 10.

\section{Results}

The results relating to typical control DNA and breast tumour DNA samples are shown in fig 1. The 91 and 110 base pair PCR products were resolved clearly using $3 \%$ metaphor agarose. For all normal DNA controls the intensity of the higher molecular weight $\beta$ globin band was greater than the intensity of the lower molecular weight c-erbB 2 band.

The study of the optimum numbers of PCR cycles showed that consistent differences in the c-erbB 2 and $\beta$ globin PCR products could be observed from 25 cycles (the sensitivity limit of the assay) to 40 cycles (the PCR plateau).

A dilution series consisting of five twofold dilutions of SKBR3 DNA into normal DNA was used for differential PCR. The ratios of c-erbB 2 to $\beta$ globin showed a linear relation with the number of copies of c-erbB 2 present (examples are shown in fig 1). This demonstrated the quantitative accuracy of this differential PCR method. Each sample was analysed at least twice and each replicate gave concordant results.

Forty two DNA samples from primary tumours and six DNA samples from nodal metastases were analysed for c-erbB 2 amplification. The distribution of c-erbB $2 / \beta$ globin ratios was bimodal. The majority of samples had ratios similar to the normal controls (within the normal range of mean +2 SD) and the remainder had from three to greater than eightfold c-erbB 2 amplification. Eleven primary tumours and lymph node metastases derived from two of these tumours had c-erbB 2 amplification. Thirty one primary tumours and lymph node metastases derived from four of these tumours had a normal c-erbB 2 copy number. Therefore, 11 of $42(26 \%)$ of these breast cancer patients had c-erbB 2 amplification in their tumours. These results are shown in relation to the tumour types in table 1 .

Clinical follow up information was available for 41 of 42 patients. The median duration of follow up was 28 months with a minimum of six months for a patient who died and a maximum of 42 months. Seven patients died of breast cancer and a further four had recurrent disease. One patient died of other causes and so was excluded from statistical analysis. 
Table 1 Summary of the tumours with c-erbB 2 amplification in relation to tumour type and grade

\begin{tabular}{lcl}
\hline Tumour type & $\begin{array}{l}\text { Total number } \\
\text { of tumours }\end{array}$ & $\begin{array}{l}\text { Tumours with } \\
\text { c-erbB 2 amplification }\end{array}$ \\
\hline Ductal grade 1 & 6 & 1 \\
Ductal grade 2 & 10 & 2 \\
Ductal grade 3 & 19 & 6 \\
Lobular & 5 & 1 \\
Special type & 1 & 0 \\
Other & 1 & 1 \\
\hline
\end{tabular}

Eleven of $40(28 \%)$ patients died of their disease or had disease recurrence and 8 of 11 $(73 \%)$ of these patients had c-erbB 2 amplification. The latter was associated strongly with early disease recurrence $(p=0.0003)$.

Twenty three patients had histological evidence of lymph node metastases at presentation and eight of these patients (35\%) died of their disease or had disease recurrence. Lymph node metastasis had an association with early disease recurrence but this did not reach statistical significance $(p=0.1)$. Six of seven $(86 \%)$ patients with c-erbB 2 amplification and lymph node metastases died of their disease or had disease recurrence.

\section{Discussion}

We present a robust differential PCR assay for the detection of c-erbB 2 amplification in human DNA. Because a numerical result is generated by an image analysis system, this technique provides objective analysis of a molecular marker, making it a good candidate for development as a routine pathology test. The PCR primers and cycle numbers have been optimised to give reproducible results that are not subject to primer dimer or plateau effect artefacts. The sensitivity of this assay, with the use of SYBR green DNA stain and the small sizes of the PCR products generated by the chosen primers make the protocol amenable to the analysis of small amounts of highly degraded DNA, as described by others. ${ }^{814}$

We found that the concentration of DNA must be standardised for each batch of samples analysed. This may be necessary to avoid differential chelation of magnesium ions by DNA and to ensure that all reactions remain within the exponential phase of the reaction. The importance of using a standard DNA template concentration for accurate differential PCR has also been shown in other studies. ${ }^{14}$

c-erbB 2 amplification was detected in 11 of $42(26 \%)$ of the primary breast tumours, a similar finding to other studies. ${ }^{911}$ Eight sets of primary breast carcinoma and their nodal metastases were analysed for gene amplification. There was no evidence for an alteration in gene copy number between the primary and secondary tumour. This suggests that any alteration to c-erbB 2 occurred before and was maintained during metastasis. No significant correlation was found between c-erbB 2 amplification and the standard histopathological prognostic markers: tumour size, type, grade, lymph node status, and oestrogen receptor status.

After a short clinical follow up, this study indicates that c-erbB 2 amplification is associated with more aggressive tumours because gene amplification was associated significantly with a poor prognosis, assessed by death and/or disease recurrence $(p=0.0003)$. This finding concurs with those of some, ${ }^{511}$ but not all, ${ }^{11}$ other studies that have used differential PCR 3 methods in retrospective analyses with longer 을 periods of clinical follow up than is presented here. In this study, the DNA analysed was from? syptomatic patients, many of whom presented $\vec{F}$ with relatively large and intermediate or high $\overline{0}$ grade tumours. It would also be interesting to 음 investigate the prognostic use of this assay in $\frac{\bar{m}}{\vec{D}}$ the often smaller and better differentiated $\stackrel{\square}{\square}$ tumours detected in the national breast screening programme.

Breast cancer is a heterogeneous disease. There may be many different mechanisms by $\vec{\omega}$ which tumours grow, metastasise, and evade $\overline{3}$ treatment response. Genetic markers that sub-? classify these tumours could help to identify those patients who would benefit most from adjuvant therapy.

We thank the Big C Appeal for funding this project and $\mathrm{Mr}$ David Ralphs and his team from the Norfolk and Norwich Hospital for providing the surgical biopsies. We are also grateful to Dr Samir Alhasan, Wayne State University, Detroit, USA and $\overrightarrow{0}$ the CRC Human Cancer Genetics Research Group, Adden- $\mathbb{D}$ brooke's Hospital, Cambridge for the gifts of the cell line DNA samples.

1 Coussens L, Yang-Feng TL, Liao YC, Chen E, Gray A, McGrath J, et al. Tyrosine kinase receptor with extensive homology to EGF receptor shares chromosomal location with neu oncogene. Science 1985;230:1132-9.

2 Schechter AL, Stern DF, Vaidyanathan L, Decker SL, Drebin JA, Greene MI, et al. The neu oncogene: an erb-B-

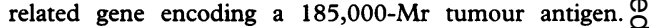
Nature 1984;312:513-16.

3 Slamon DJ, Clark GM, Wong SG, Levin WJ, Ullrich A, $\overline{\bar{O}}$ McGuire WL. Human breast cancer: correlation of relapse 3 and survival with amplification of the HER-2/neu oncogene. Science 1987;235:177-82.

4 Gullick WJ, Love SB, Wright C, Barnes DM, Gusterson B, Harris $\mathrm{AL}$, et al. c-erbB2 protein overexpression in breast cancer is a risk factor in patients with involved and? uninvolved lymph nodes. Br $\mathcal{F}$ Cancer 1991;63:434-8.

5 Lonn U, Lonn S, Nilsson B, Silversward C, Stenkvist B. Demonstration of gene-amplification by PCR in archival $O$ paraffin-embedded breast cancer tissue. Breast Cancer Res Treat 1994;30:147-52

6 Molland JG, Barraclough BH, Gebski V, Milliken J, Bilous 을 $M$. Prognostic significance of c-erbB2 oncogene in axillary node-negative breast cancer. Aust NZ f Surg 1996;66:64-응 70

7 Frye RA, Benz CC, Liu E. Detection of amplified oncogenes by differential polymerase chain reaction. Onco-o gene 1989;4:1153-7.

8 Gramlich TL, Cohen C, Fritsch C, DeRose, PB, Gansler E. N Evaluation of c-erbB2 amplification in breast carcinoma by $\omega$ differential polymerase chain reaction. Am $\mathcal{f}$ Clin Pathol 1994;101:493-9.

9 An H, Niederacher D, Beckmann MW, Gohring UJ, Scharl A, Picard F, et al. ERBB2 gene amplification detected by fluorescent differential polymerase chain reaction in :paraffin-embedded breast carcinoma tissues. Int $\mathcal{F}$ Cancer 1995;64:291-7.

10 Friedrichs K, Lohmann D, Hofler H. Detection of HER-2 $\underset{\vec{D}}{\vec{d}}$ oncogene amplification in breast cancer by differential polymerase chain reaction from single cryosections. Vir- $\mathbb{D}$ chows Archiv B Cell Pathol 1993;64:209-12.

11 Lonn U, Lonn S, Nilsson B, Stenkvist B. Prognostic value of erb-B2 and myc amplification in breast cancer imprints. Cancer 1995;75:2681-7.

12 Worsley SD, Jennings BA, Khalil KH, Mole M, Girling AC. Cyclin D1 amplification and expression in human breastē carcinoma: correlation with histological prognostic mark- $\supset$ ers and oestrogen receptor expression. f Clin Pathol: $M o l=$ ers and oestrogen recep
Pathol 1996;49:M46-50.

13 Killick SB, McCann BG. Osteosarcoma of the breast associated with fibroadenoma. Clin Oncol 1995;7:132-3.

14 Neubauer A, Neubauer B, He M, Effert P, Iglehart D, Frye $\mathrm{RA}$, et al. Analysis of gene amplification in archival tissue by differential polymerase chain reaction. Oncogene 1992;7: 1019-25. 